\title{
Synthesis of Linoleoyl Ethanolamide
}

\author{
Xiaosan Wang ${ }^{1,2}$, Yan Chen ${ }^{1}$, Qingzhe Jin $^{1}$, Jianhua Huang ${ }^{1}$ and Xingguo Wang ${ }^{1 *}$ \\ ${ }^{1}$ State Key Laboratory of Food Science and Technology, School of Food Science and Technology, Jiangnan University, NO. 1800 Lihu Road, \\ Wuxi, Jiangsu 214122, P. R. China \\ ${ }^{2}$ Department of Food Science and Human Nutrition, lowa State University, 2312 Food Science Building, Ames, IA 50011, USA
}

\begin{abstract}
Linoleoyl ethanolamide has been showed to serve as a new and additional class of endogenous signaling molecule and exhibited a variety of biological activities in cells and tissues. Herein, we reported an effective method for the synthesis of linoleoyl ethanolamide. Enzymatic and chemical syntheses of linoleoyl ethanolamide were first compared and then reaction conditions were optimized. When the reaction was conducted at $30^{\circ} \mathrm{C}$ for $1 \mathrm{~h}$ by reacting $0.5 \mathrm{mmol}$ methyl linoleate with $5 \mathrm{mmol}$ ethanolamine in the presence of $15 \mu \mathrm{L}, 5.4 \mathrm{~mol} / \mathrm{L}$ sodium methoxide in methanol as catalyst, $97.2 \%$ linoleoyl ethanolamide was produced in the crude reaction mixture without further purification after the removal of excess ethanolamine. Additionally, the reaction can be conducted on a large scale, which resulted in the formation of $95.9 \%$ linoleoyl ethanolamide. Compared to previous studies, the amidation reaction between methyl linoleate and ethanolamine with sodium methoxide as catalyst for the synthesis of linoleoyl ethanolamide is more effective and faster. In addition, the reaction is scalable and reaction conditions are mild. This is the first time to use methyl linoleate to synthesize linoleoyl ethanolamide. Commercial linoleoyl ethanolamide is very expensive. However, the scalability and ease for such synthesis make it possible to study the biological and nutritional functions of the cannabinoid-like linoleoyl ethanolamide in animal or human subjects.
\end{abstract}

Key words: amidation reaction, linoleoyl ethanolamide, sodium methoxide, synthesis

\section{Introduction}

Fatty acid ethanolamides are an important class of alkanolamides that function as nonionic surfactants and have a wide range of applications in the lubricants, surfactants and detergents, cosmetics, and other industries ${ }^{1,2)}$. They are used as anti-slip and anti-block additives for polyethylene films, water repellants for textiles, coatings for paper, mold release agents, lubricant additives, printing ink additives, defoaming agents and flow improvers ${ }^{3)}$.

Fatty acid ethanolamides are a family of lipids naturally found in both plant and animal tissues ${ }^{4)}$. Ethanolamides from saturated $\mathrm{C}_{12}$ to $\mathrm{C}_{18}$ and unsaturated $\mathrm{C}_{18}$ are major components in seeds ${ }^{5)}$. In addition, anandamide which is the amide of arachidonic acid and ethanolamine is present as a minor component in tissue ${ }^{6)}$. In addition to applications as nonionic surfactants, certain fatty acid ethanolamides are lipid mediators in animals and plants ${ }^{4}$. For example, palmitoyl ethanolamide was shown to have antiinflammatory activity ${ }^{7)}$. It may also play a key role in the regulation of complex systems involved in neuroprotective and anti-nociceptive effects in rats and mice ${ }^{8)}$. Linoleoyl ethanolamide, which is formed through enzymatic hydrolysis of the corresponding acyl phosphatidyl ethanolamides by phospolipase $\mathrm{D}^{9)}$ is anandamide homologues ${ }^{10)}$. However, linoleoyl ethanolamide has been found to only weakly bind G-protein-coupled cannabinoid receptors of type-1 $\left(\mathrm{CB}_{1}\right)$ and $\mathrm{CB}_{2}$ receptors ${ }^{11)}$, and is 4 -fold less potent than anandamide at causing catalepsy in mice and it does not prolong sleep time ${ }^{8)}$. In addition, linoleoyl ethanolamide competitively inhibits the hydrolysis of anandamide ${ }^{12)}$ and may be involved in the regulation of food intake by selective prolongation of feeding latency and post-meal inter$\mathrm{val}^{8)}$.

In general, fatty acid ethanolamides can be synthesized from ethanolamine with a fatty acyl donor, such as free fatty acids ${ }^{13-15)}$, fatty acid chlorides ${ }^{16)}$, native oils ${ }^{17)}$ and fatty acid vinyl esters ${ }^{18)}$. In general, using fatty acid chlorides as acyl donor to synthesize fatty acid ethanolamides is more expensive and effective than other acyl donors. However, Fatty acid chloride is a corrosive and relatively toxic chemical which may dramatically affect the bioactivity of fatty acid ethanolamide if it is not fully removed after purification. Using native oils as acyl donor to synthesize fatty acid ethanolamide aims to obtain nonionic surfac$\operatorname{tants}^{19)}$, while vinyl linoleate is commercially unavailable The methods using free fatty acids as acyl donor for syn-

\footnotetext{
* Correspondence to: Xingguo Wang, Ph.D. Professor, State Key Laboratory of Food Science and Technology, School of Food Science and Technology, Jiangnan University, NO. 1800 Lihu Road, Wuxi, Jiangsu 214122, P. R. China

E-mail: wxstongxue@163.com

Accepted January 28, 2013 (received for review October 29, 2012)

Journal of Oleo Science ISSN 1345-8957 print / ISSN 1347-3352 online

http://www.jstage.jst.go.jp/browse/jos/ http://mc.manusriptcentral.com/jjocs
} 
thesis of fatty acid ethanolamides are more popular compared to other acyl donors. It has been reported that Novozym 435 lipase is an effective biocatalyst for the amidation reaction between free fatty acids and ethanolamine ${ }^{14,20)}$ and usually results in a better product's quality in color, yield and odor compared to other methods ${ }^{211}$. In addition, sodium methoxide can also be applied to catalyze the amidation reaction at low or high temperature ${ }^{15,17)}$, while the amidation reaction conducted in absence of catalysts needs a higher temperature ${ }^{2)}$ and usually causes various problems in color and odor even though the addition of deodorizers and antioxidants to the process has been suggested to improve product's quality ${ }^{21)}$. The main disadvantage using free fatty acid as acyl donor to synthesize fatty acid ethanolamide is the formation of salt ion-pair from equivalent moles of ethanolamine and free fatty $\operatorname{acid}^{21)}$. The salt is organic solvent insoluble, which may make the amidation reaction less effective in solvent system compared to solvent-free system ${ }^{14)}$. However, synthesis of saturated fatty acid ethanolamides with more than 12 carbon fatty acid chain is not feasible in solvent-free system with lipase as catalyst since fatty acid ethanolamides have much high melting point, suggesting a high reaction temperature, which will result in the inactivation of enzyme ${ }^{21}$. Thus, based on these considerations, fatty acid methyl esters may be the better acyl donors to synthesize fatty acid ethanolamides compared to free fatty acids.

Many publications have reported the synthesis of fatty acid ethanolamides, but most of them focus on the synthesis of fatty acid ethanolamides for surfactant purposes. Synthesis of highly pure fatty acid ethanolamides as lipid mediators receives little attention, but with the increasing knowledge and interest in fatty acid ethanolamides in biological and nutritional function aspects. An effective method for synthesis of fatty acid ethanolamides is necessary since commercially pure fatty acid ethanolamides are very expensive. For example, the price of linoleoyl ethanolamide from Sigma-Aldrich is $\$ 224.5$ per $10 \mathrm{mg}$, which limits its study as lipid mediators.

In the present study, we compared enzymatic and chemical syntheses of linoleoyl ethanolamide using methyl linoleate as acyl donor and then reaction conditions were optimized. About 97\% linoleoyl ethanolamide was obtained after the removal of excess ethanolamine. Our method for the synthesis of linoleoyl ethanolamide on a large scale makes it possible to investigate biological activities of linoleoyl ethanolamide in animal and human subjects.

\section{Materials and methods}

\subsection{Materials}

Methyl linoleate $(>99 \%)$, ethanolamine $(>99 \%)$ were purchased from Sinopharm Chemical Reagent Co. Ltd.
(Shanghai, China). Linoleoyl ethanolamide standard (> 98\%) was purchased from the Sigma-Aldrich Chemical Co. Ltd. (Shanghai, China). Novozym 435 lipase from Candida antarctica was obtained from Novozymes (Beijing, China). This is an immobilized lipase and has the declared activity of 10,000 PLU (propyl laurate unit)/g by Novozymes. All other reagents were of analytical grade and were purchased from Sinopharm Chemical Reagent Co. Ltd.

\subsection{Enzymatic and chemical syntheses of linoleoyl etha- nolamide \\ Enzymatic synthesis: Ethanolamine $(0.5 \mathrm{mmol})$ was} mixed with methyl linoleate $(0.5 \mathrm{mmol})$ in hexane $(4 \mathrm{~mL})$ in a $10-\mathrm{mL}$ round bottom flask. The reaction was started by adding 0.05 g Novozym 435 and conducted with agitation at $30^{\circ} \mathrm{C}$ for 1.5 and $5 \mathrm{~h}$. The lipase was filtrated from the resulting mixture and the solvent was evaporated under the reduced pressure. Linoleoyl ethanolamide was then derivatized and quantified by GC as described in the following section. Hexane was also replaced with the same amount of ethanolamine to investigate the solvent effect on synthesis of linoleoyl ethanolamide.

Chemical synthesis: Ethanolamine (5 mmol)was mixed with methyl linoleate $(0.5 \mathrm{mmol})$ in a $10-\mathrm{mL}$ round bottom flask. The reaction was started by adding $10 \mu \mathrm{L}, 5.4 \mathrm{~mol} / \mathrm{L}$ sodium methoxide in methanol and conducted with agitation at $30^{\circ} \mathrm{C}$ for 1.5 and $5 \mathrm{~h}$. The resulting mixture was then mixed with $5 \% \mathrm{HCl}$ in distilled water at $6^{\circ} \mathrm{C}$ for $1 \mathrm{~h}$ to fully remove the excess ethanolamine and $\mathrm{HCl}$ was removed by water washing.

\subsection{Optimization of synthesis of linoleoyl ethanolamide}

Experimental design of optimization of the amidation reaction between ethanolamine and methyl linoleate is outlined in Table 1. The effects of solvent, catalyst amount, ethanolamine amount, reaction temperature and time were investigated.

Effect of solvent: Optimization of solvent was conducted by reacting $0.5 \mathrm{mmol}$ methyl linoleate with $5 \mathrm{mmol}$ ethanolamine at $30^{\circ} \mathrm{C}$ for $1 \mathrm{~h}$ in $0.4 \mathrm{~mL}$ hexane, dichloromethane or ethanolamine with $10 \mu \mathrm{L}, 5.4 \mathrm{~mol} / \mathrm{L}$ sodium methoxide in methanol as catalyst.

Effect of catalyst amount: Optimization of catalyst amount was conducted by reacting $0.5 \mathrm{mmol}$ methyl linoleate with $5 \mathrm{mmol}$ ethanolamine at $30^{\circ} \mathrm{C}$ for $1 \mathrm{~h}$ with 5,10 , 15,20 and $25 \mu \mathrm{L}, 5.4 \mathrm{~mol} / \mathrm{L}$ sodium methoxide in methanol as catalyst.

Effect of ethanolamine amount: Optimization of ethanolamine amount was conducted by reacting $0.5 \mathrm{mmol}$ methyl linoleate with $2.5,5,7.5$ and $10 \mathrm{mmol}$ ethanolamine at $30^{\circ} \mathrm{C}$ for $1 \mathrm{~h}$ with $15 \mu \mathrm{L}$ sodium methoxide solution as catalyst.

Effect of reaction temperature: Optimization of reaction temperature was conducted by reacting $0.5 \mathrm{mmol}$ methyl linoleate with $5 \mathrm{mmol}$ ethanolamine at 20, 30, 40, 50 and 
Table 1 Experimental design of the amidation reaction between methyl linoleate and ethanolamine ${ }^{a}$.

\begin{tabular}{cccccc}
\hline Level & Solvent & Catalyst $[\mu \mathrm{L}]$ & $\begin{array}{c}\text { Ethanolamine } \\
{[\mathrm{mmol}]}\end{array}$ & $\begin{array}{c}\text { Temperature } \\
{\left[{ }^{\circ} \mathrm{C}\right]}\end{array}$ & Time $[\mathrm{h}]$ \\
\hline 1 & Hexane & 5 & 2.5 & 20 & 0.5 \\
2 & Dichloromethane & 10 & 5.0 & 30 & 1.0 \\
3 & Ethanolamine & 15 & 7.5 & 40 & 1.5 \\
4 & & 20 & 10.0 & 50 & 2.0 \\
5 & & 25 & & 60 & 2.5 \\
\hline
\end{tabular}

a) All reactions were conducted by reacting $5 \mathrm{mmol}$ ethanolamine with $0.5 \mathrm{mmol}$ methyl linoleate at $30^{\circ} \mathrm{C}$ for $1 \mathrm{~h}$ with $15 \mu \mathrm{L}$ sodium methoxide solution as catalyst unless otherwise stated.

$60^{\circ} \mathrm{C}$ for $1 \mathrm{~h}$ with $15 \mu \mathrm{L}$ sodium methoxide solution as catalyst.

Effect of reaction time: Optimization of reaction time was conducted by reacting $0.5 \mathrm{mmol}$ methyl linoleate with 5 mmol ethanolamine at $30^{\circ} \mathrm{C}$ for $0.5,1,1.5,2$ and $2.5 \mathrm{~h}$ with $15 \mu \mathrm{L}$ sodium methoxide solution as catalyst.

\subsection{Synthesis of linoleoyl ethanolamide on a large scale}

The reaction conditions used were exactly the same as the optimal conditions obtained on $0.5 \mathrm{mmol}$ scale. Methyl linoleate $(25 \mathrm{mmol})$ was mixed with ethanolamine (125 mmol) at $30^{\circ} \mathrm{C}$ for $1 \mathrm{~h}$ with $15 \mu \mathrm{L}$ sodium methoxide catalyst. The resulting mixture was then mixed with $5 \% \mathrm{HCl}$ in distilled water and placed at $6{ }^{\circ} \mathrm{C}$ for $1 \mathrm{~h}$ to recrystallize linoleoyl ethanolamide and $\mathrm{HCl}$ was removed by water washing. The processes were repeated for three times to fully remove the excess ethanolamine.

All optimization experiments were conducted in duplicate, and the data are expressed as mean of two values

\subsection{Procedure for preparation of linoleoyl ethanolamide derivative for $\mathrm{GC}$ analysis}

The anhydrous reaction mixture containing linoleoyl ethanolamide (about $3 \mathrm{mg}$ ) was placed in $2 \mathrm{~mL}$ glass vial and treated with pyridine $(0.5 \mathrm{~mL})$, hexamethyldisilazane $(0.15 \mathrm{~mL})$ and trimethylchlorosilane $(0.05 \mathrm{~mL})$. The mixture was shaken for $15-30 \mathrm{sec}$ and then allowed to stand for $10 \mathrm{~min}$.

\subsection{Quantitative analysis of linoleoyl ethanolamide}

GC was employed to quantify linoleoyl ethanolamide. The peak at 10.7-10.8 min(Fig. 1) was attributed to the silylation reagent rather than sample based on retention times determined by control injections. This observation was also reported in other studies ${ }^{18,22)}$. Linoleoyl ethanolamide content in the reaction mixture can be calculated based on the area ratio of linoleoyl ethanolamide peak and total sample peaks.

Linoleoyl ethanolamide was identified and quantified by GC-14B gas chromatography (Shimadzu, Tokyo, Japan) equipped with a flame ionization detector (FID) using a 30

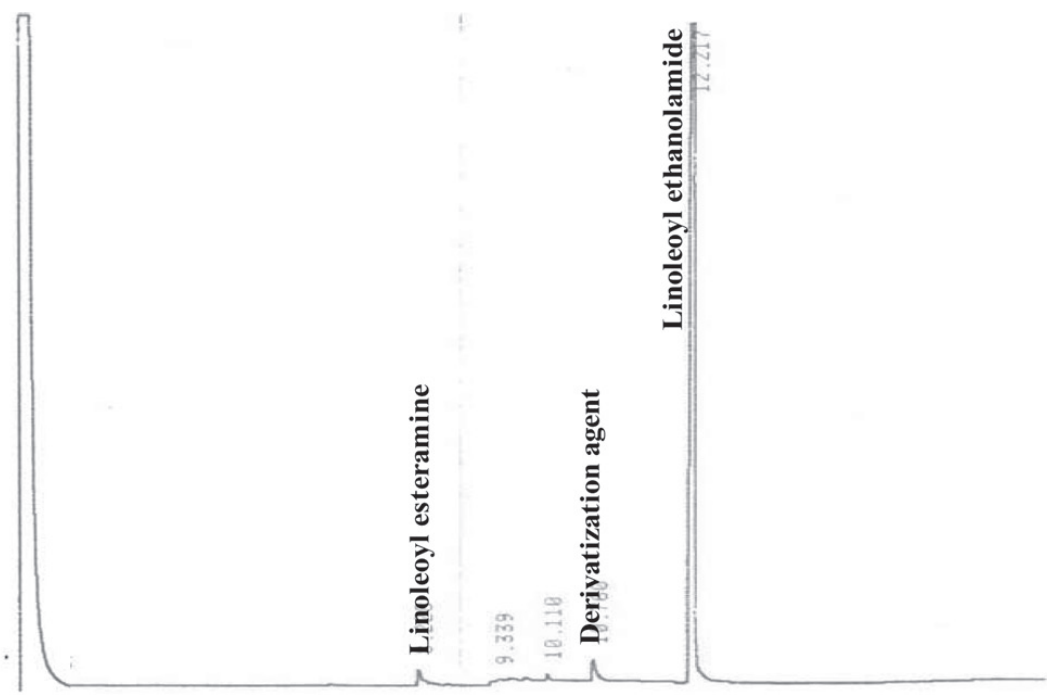

Fig. 1 GC chromatogram of synthetic linoleoyl ethanolamide. 
$\mathrm{m} \times 0.25 \mathrm{~mm} \times 0.25 \mu \mathrm{m}($ length $\times \mathrm{I} . \mathrm{D} \times$ film thickness $)$ fusedsilica capillary column PEG-20000. The oven temperature was programmed from 150 to $245^{\circ} \mathrm{C}$ at a rate of $10^{\circ} \mathrm{C} / \mathrm{min}$, and then held at $245^{\circ} \mathrm{C}$ for $15 \mathrm{~min}$. Injector and detector temperatures were set at $250^{\circ} \mathrm{C}$.

\subsection{Qualitative analysis of linoleoyl ethanolamide}

Linoleoyl ethanolamide was used as external standards to qualify the peak based on the retention time. ${ }^{1} \mathrm{H}-\mathrm{NMR}$ qualitative analysis of linoleoyl ethanolamide was done in $\mathrm{CDCl}_{3}$ as solvent using tetramethyl silane(TMS) as internal standard with a Bruker NMR spectrometer (Avance III 400 $\mathrm{MHz}$, Switzerland) operating at $400 \mathrm{MHz}$.

\section{Results and discussion}

\subsection{Enzymatic and chemical syntheses of linoleoyl etha- nolamide}

The results are presented in Table 2 . When the enzymatic reaction was conducted by reacting $0.5 \mathrm{mmol}$ ethanolamine with $0.5 \mathrm{mmol}$ methyl linoleate in $4 \mathrm{~mL}$ hexane at $30^{\circ} \mathrm{C}$ with 0.05 g Novozym 435 as catalyst, no linoleoyl ethanolamide was produced. In the previous research, pure linoleoyl ethanolamide was obtained by conducting the amidation reaction at $40^{\circ} \mathrm{C}$ between linoleic acid and ethanolamine in hexane with $65 \%$ Novozym 435 load (w/w, relative to total reactants) after purification by preparative HPLC $^{14)}$. In the present study, no linoleoyl ethanolamide formed may be due to specificity of lipase to free fatty acids rather than fatty acid methyl esters and low lipase load. However, the addition amount of Novozym 435 (10\%, $\mathrm{w} / \mathrm{w}$, relative to total reactants) in the present study was reasonable ${ }^{23,24)}$. When hexane was replaced with excess ethanolamine, there was 40.8 and $48.8 \%$ linoleoyl ethanolamide produced after 1.5 and $5 \mathrm{~h}$, respectively. Low linoleoyl ethanolamide content in the product may result from the polar solvent, which affected the enzyme activity ${ }^{25}$. However, ethanolamine may serve as catalyst for the amidation reaction ${ }^{17)}$.
When the chemical reaction was conducted by reacting $5 \mathrm{mmol}$ ethanolamine with $0.5 \mathrm{mmol}$ methyl linoleate at $30^{\circ} \mathrm{C}$ with sodium methoxide as catalyst, there was 95.1 and $94.8 \%$ linoleoyl ethanolamide produced after 1.5 and 5 h, respectively (Fig. 1). Linoleoyl esteramine and ethanolamide contents in the crude reaction mixture increased and decreased, respectively with increasing reaction time. Sodium methoxide was an effective catalyst for the amidation reaction and the results agreed well with the previous studies $^{17,18)}$. In general, the transesterification reaction between ethanolamine and methyl linoleate will happen and thus result in the formation of esteramine even though the amidation reaction is dominant (Fig. 2). Therefore, the optimization of reaction conditions was necessary to reduce the formation of esteramine and increase the conversion of methyl linoleate in the further experiments.

${ }^{1} \mathrm{H}$ NMR spectroscopy of linoleoyl ethanolamide shows as followings: $\delta 0.80\left(\mathrm{t}, 3 \mathrm{H}, \mathrm{CH}_{3}\right), 1.21\left(\mathrm{~m}, 14 \mathrm{H}, \mathrm{CH}_{3}\left(\mathrm{CH}_{2}\right)_{3}+\right.$ $\left.=\mathrm{CHCH}_{2}\left(\mathrm{CH}_{2}\right)_{4}\right), 1.51\left(\mathrm{~m}, 2 \mathrm{H}, \mathrm{CH}_{2} \mathrm{CH}_{2} \mathrm{C}=\mathrm{O}\right), 1.95(\mathrm{~m}, 4 \mathrm{H}$, $\left.\mathrm{C}_{2} \mathrm{CH}=\mathrm{CHCH}_{2} \mathrm{CH}=\mathrm{CHC}_{2}\right), 2.10\left(\mathrm{t}, 2 \mathrm{H}, \mathrm{CH}_{2} \mathrm{C}=\mathrm{O}\right), 2.67$ $\left(\mathrm{t}, 2 \mathrm{H}, \mathrm{HC}=\mathrm{CHC} \boldsymbol{H}_{2} \mathrm{CH}=\mathrm{CH}\right), 3.23\left(\mathrm{~m}, 2 \mathrm{H}, \mathrm{CH}_{2} \mathrm{NH}\right), 3.58$ $\left(\mathrm{t}, 2 \mathrm{H}, \mathrm{C} \boldsymbol{H}_{2} \mathrm{OH}\right), 5.25(\mathrm{~m}, 4 \mathrm{H}, 2 \times \mathrm{HC}=\mathrm{CH}), 6.17(\mathrm{~s}, \mathrm{br}, 1 \mathrm{H}$, $\mathrm{N} \boldsymbol{H})$. No ${ }^{1} \mathrm{H}$ NMR peak of $-\mathrm{COOC} \boldsymbol{H}_{2} \mathrm{CH}_{2} \mathrm{NH}_{2}(\delta$ 4.2-4.4, $2 \mathrm{H})$ can be observed or $-\mathrm{COOCH}_{2} \mathrm{CH}_{2} \mathrm{NH}_{2}$ can be observed. Therefore, we confirmed the structure and purity of linoleoyl ethanolamide.

\subsection{Optimization of synthesis of linoleoyl ethanolamide}

The effects of solvent, addition amount of sodium methoxide and ethanolamine, reaction temperature and time on mixture composition were investigated. The results are presented in Fig. 3 and Fig. 4. Data are expressed as mean of two values.

Solvent affects the solubility of product and catalyst due to the differences in solvent polarity. The amidation reaction conducted in excess ethanolamine resulted in a higher linoleoyl ethanolamide content compared to those in hexane and dichloromethane. Linoleoyl ethanolamide and esteramine contents were about 95 and $0.8 \%$, respectively, in the crude reaction mixture after $1 \mathrm{~h}$ when excess etha-

Table 2 Comparison of enzymatic and chemical syntheses of linoleoyl ethanolamide ${ }^{\text {a) }}$.

\begin{tabular}{lccrrrr}
\hline \multirow{2}{*}{ Reaction mixture } & \multicolumn{3}{c}{ Enzymatic synthesis } & \multicolumn{2}{c}{ Chemical synthesis } \\
\cline { 2 - 7 } & \multicolumn{2}{c}{ Hexane } & \multicolumn{2}{c}{ Ethanolamine } & \multicolumn{2}{c}{ Ethanolamine } \\
\cline { 2 - 7 } & $1.5 \mathrm{~h}$ & $5 \mathrm{~h}$ & $1.5 \mathrm{~h}$ & $5 \mathrm{~h}$ & $1.5 \mathrm{~h}$ & $5 \mathrm{~h}$ \\
\hline Linoleoyl ethanolamide [\%] & 0 & 0 & 40.8 & 48.8 & 95.1 & 94.8 \\
Linoleoyl esteramine [\%] & 0 & 0 & 7.1 & 6.9 & 1.6 & 2.5 \\
Methyl linoleate [\%] & 100 & 100 & 51.4 & 43.2 & 1.7 & 0.9 \\
\hline
\end{tabular}

a) The enzymatic reaction was conducted by reacting $0.5 \mathrm{mmol}$ ethanolamine with $0.5 \mathrm{mmol}$ methyl linoleate in $4 \mathrm{~mL}$ solvent at $30^{\circ} \mathrm{C}$ with $0.05 \mathrm{~g}$ Novozym 435 as catalyst; the chemical reaction was conducted by reacting $5 \mathrm{mmol}$ ethanolamine with $0.5 \mathrm{mmol}$ methyl linoleate at $30^{\circ} \mathrm{C}$ with sodium methoxide as catalyst 
Main reaction

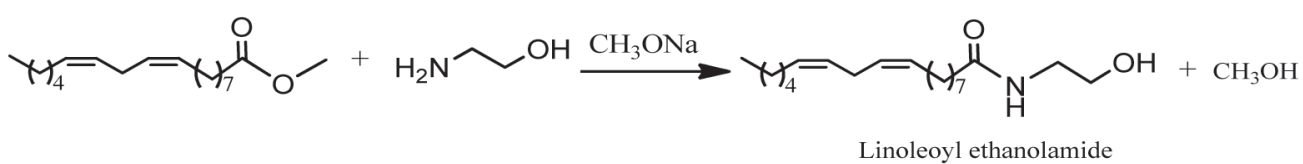

Side reactions
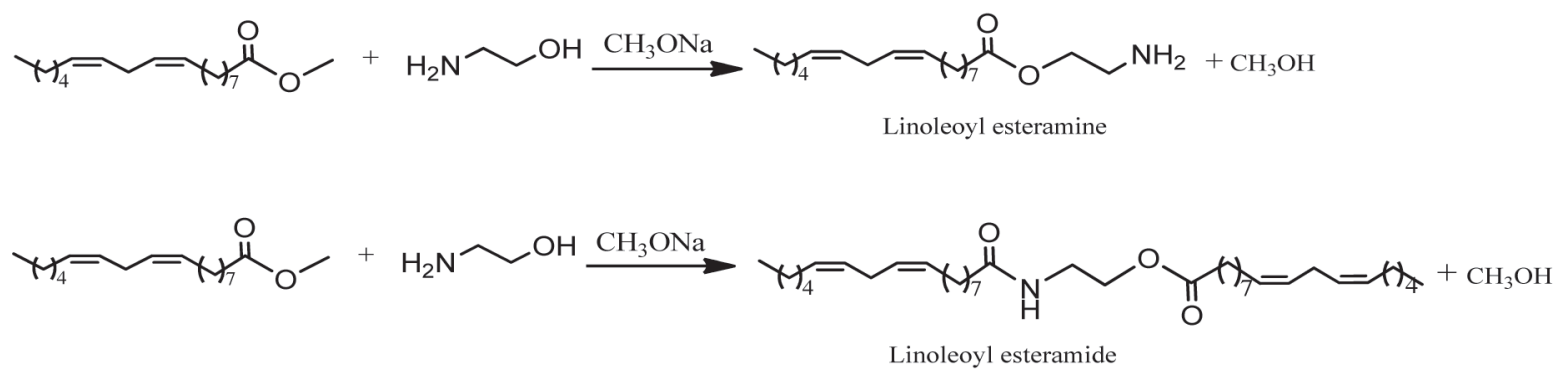

Fig. 2 Possible reaction routes between methyl linoleate and ethanolamine.

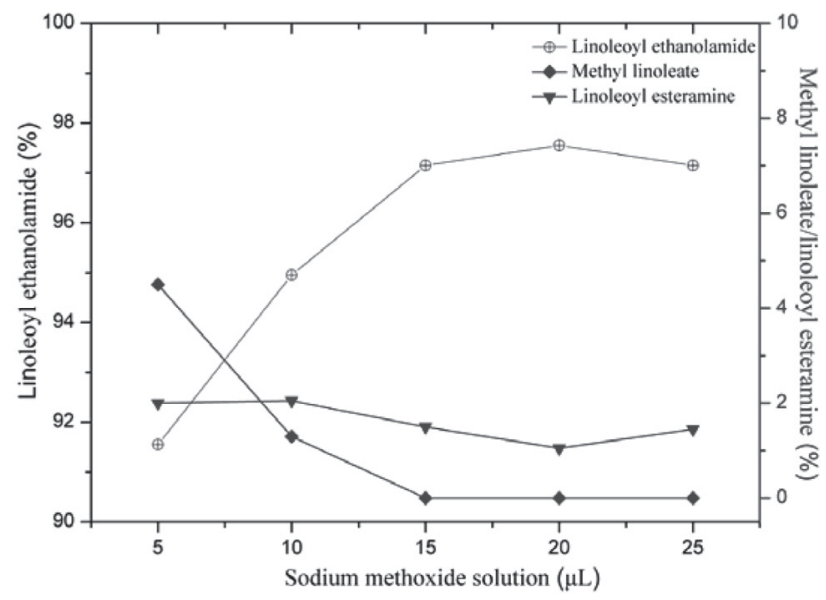

Fig. 3 The effect of sodium methoxide amount on composition of crude reaction mixture.

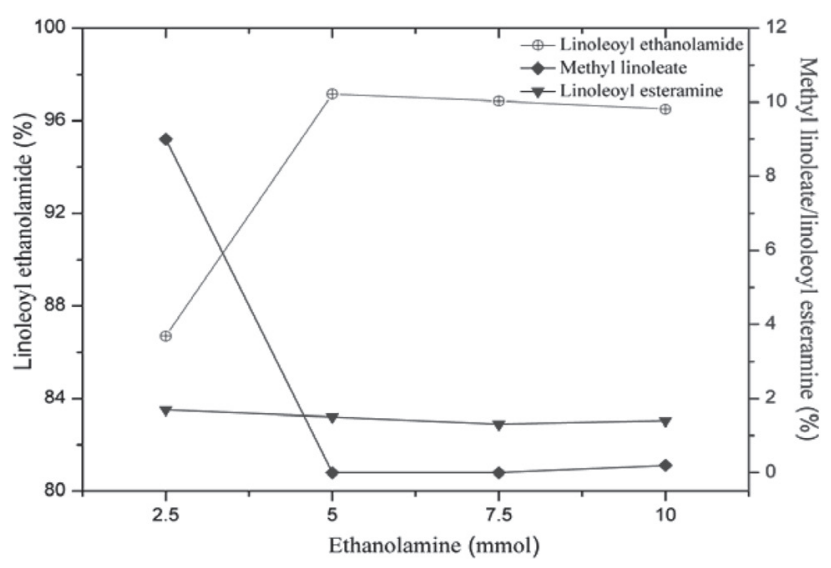

Fig. 4 The effect of ethanolamine amount on composition of crude reaction mixture. nolamine was used as solvent. High linoleoyl ethanolamide content resulting from high conversion of methyl linoleate was probably because ethanolamine was a better solvent to dissolve the reactants and catalyst. In addition, as mentioned above, excess ethanolamine may serve as catalyst and thus promoted the amidation reaction ${ }^{17)}$. No significant differences were observed among different solvents after 1 $\mathrm{h}$ for linoleoyl esteramine content in the crude reaction mixture. Finally, excess ethanolamine was selected as solvent for the further reactions.

Catalyst amount affects effectiveness of the amidation reaction. Linoleoyl ethanolamide tended to increase with increasing addition amount of catalyst (Fig. 3) . Accordingly, methyl linoleate tended to decrease, while linoleoyl esteramine tended to keep constant in reaction mixture. When the amidation reaction between methyl linoleate and ethanolamine was conducted at $30^{\circ} \mathrm{C}$ in $15 \mu \mathrm{L}$ sodium methoxide in methanol for $1 \mathrm{~h}$, there were $97.2 \%$ linoleoyl ethanolamide and $1.5 \%$ linoleoyl esteramine produced, while $100 \%$ methyl linoleate was converted. Increasing catalyst amount further did not cause an increase in linoleoyl ethanolamide content in final product. Finally, $15 \mu \mathrm{L}, 5.4 \mathrm{~mol} / \mathrm{L}$ sodium methoxide in methanol was selected for further optimization experiments.

Ethanolamine amount affects the concentration of reactants and catalyst. In addition, ethanolamine amount also affects the solubility of product and reactants. Linoleoyl ethanolamide content was significantly higher in final products when $5 \mathrm{mmol}$ ethanolamine was added into the reaction system compared to $2.5 \mathrm{mmol}$ ethanolamine(Fig. 4). No significant differences in linoleoyl ethanolamide content were observed when ethanolamine was increased further from 5 to $10 \mathrm{mmol}$. In contrast, methyl linoleate content was significantly decreased in final product from $9 \%$ to 0 
when ethanolamine was increased from $2.5 \mathrm{mmol}$ to more, while linoleoyl esteramine content basically kept constant regardless of ethanolamine amount. Thus, 5 -fold excess ethanolamine as solvent was not enough to dissolve the reactants even though less solvent used was beneficial to keep higher catalyst concentration. Finally, $5 \mathrm{mmol}$ ethanolamine was selected as optimal condition for the further experiments.

Temperature affects the solubility of reactants and product in solvent and the reaction rate. Overall, no significant differences were observed in linoleoyl ethanolamide content with the changes in temperature. However, the reactions conducted at the temperatures above $30^{\circ} \mathrm{C}$ tended to increase the formation of esteramine and decrease the formation of ethanolamide, while methyl linoleate content in the crude reaction mixture was always zero at the temperatures above $30^{\circ} \mathrm{C}$. Thus, $30^{\circ} \mathrm{C}$ was selected as optimal temperature.

The response of linoleoyl ethanolamide, methyl linoleate and linoleoyl esteramine on reaction time was similar with temperature. However, there were a significantly increase in linoleoyl ethanolamide content when reaction time was increased from 0.5 to $1 \mathrm{~h}$. No significant differences were observed when reaction time was increased further. Linoleoyl esteramine tended to increase with the increase in reaction time, while methyl linoleate significantly decreased from 0.5 to $1 \mathrm{~h}$ and then keep constant after $1 \mathrm{~h}$, suggesting that $100 \%$ methyl linoleate have been converted. Thus, $1 \mathrm{~h}$ was selected as optimal reaction time.

After all reaction conditions were confirmed, the reaction was conducted with agitation at $30^{\circ} \mathrm{C}$ for $1 \mathrm{~h}$ by reacting $0.5 \mathrm{mmol}$ methyl linoleate with $5 \mathrm{mmol}$ ethanolamine in the presence of $15 \mu \mathrm{L}, 5.4 \mathrm{~mol} / \mathrm{L}$ sodium methoxide in methanol as catalyst. There was about $97 \%$ linoleoyl ethanolamide produced without further purification after removal of excess ethanolamine by washing in 5\% $\mathrm{HCl}$ in distilled water and $\mathrm{HCl}$ was removed by water washing.

\subsection{Synthesis of linoleoyl ethanolamide on a large scale}

Synthesis of linoleoyl ethanolamide was also conducted on a large scale. There was $95.9 \%$ linoleoyl ethanolamide produced in the crude reaction mixture after removal of excess ethanolamine, suggesting that our method for the synthesis of linoleoyl ethanolamide was scalable.

There have been some publications reported the synthesis of fatty acid ethanolamides ${ }^{13,14,17-21)}$. However, for most studies, these researchers aimed to obtain fatty acid ethanolamides for the surfactant purposes. These reactions were conducted either in solvent-free system or in the solvent system. In general, Reactions conducted in solvent system on a large scale can not result in the formation of highly pure fatty acid ethanolamide without purification steps $^{14,17)}$ while in our method, pure linoleoyl ethanolamide can be obtained without further purification after removal of excess ethanolamine. The synthesis of linoleoyl ethanolamide can also be conducted in solvent-free system using lipase as catalyst. However, reaction temperature depends on the melting point of fatty acid ethanolamide in order to keep the reactants and product liquid in the reaction mixture $^{21)}$. In general, the melting point of fatty acid ethanolamide with more than 12 carbons in fatty acid chain is more than $90^{\circ} \mathrm{C}^{21}$. Therefore, our preliminary experiments showed that high reaction temperature resulted in the inactivation of lipase and affected the product's color and odor (data not shown). In addition, unsaturated fatty acids and their ethanolamides may be oxidized at such high temperature. In our method, synthesis of linoleoyl ethanolamide was conducted in much mild condition. In previous studies, only Plastina et al. ${ }^{14)}$ reported the synthesis of linoleoyl ethanolamide between linoleic acid and ethanolamide. However, amidation reaction between linoleic acid and ethanolamine resulted in a less yield and conversion compared to our study probably because ion pair salt formed between linoleic acid and ethanolamine was insoluble in solvent. Thus, using fatty acid methyl esters as acyl donor may be a better acyl donor compared to free fatty acids for the synthesis of fatty acid ethanolamides.

\section{Conclusions}

In conclusion, fatty acid ethanolamides have been found in many foods ${ }^{12,26)}$. Our method for the synthesis of linoleoyl ethanolamide is important since commercial linoleoyl ethanolamide is very expensive, which limits its study as lipid mediator in animal and human experiments. In addition, our method is simpler due to no further purification after removal of excess ethanolamine by $5 \% \mathrm{HCl}$ in distilled water compared to purification of linoleoyl ethanolamide by preparative HPLC described by Plastina et al. ${ }^{14)}$, more effective and efficient due to the formation of highly pure linoleoyl ethanolamide within $1 \mathrm{~h}$ compared to 6 to 24 $\mathrm{h}$ in previous studies ${ }^{2,14,21)}$, milder due to low temperature and scalable. Finally, fatty acid methyl ester as acyl donor to synthesize fatty acid ethanolamide receives little attention.

\section{Acknowledgements}

The authors would like to thank Zong Meng for his guidance and assistance.

\section{References}

1) Bilyk, A.; Bistline, R. G.; Piazza, G. J.; Feairheller, S. H.; Haas, M. J. A novel technique for the preparation of 
secondary fatty amides. J. Am. Oil Chem. Soc. 69, 488-491 (1992).

2) Liu, K. J.; Nag, A.; Shaw, J. F. Lipase-catalyzed synthesis of fatty acid diethanolamides. J. Agric. Food Chem. 49, 5761-5764(2001).

3) Feairheller, S.; Bistline, R.; Bilyk, A.; Dudley, R.; Kozempel, M.; Haas, M. A novel technique for the preparation of secondary fatty amides. J. Am. Oil Chem. Soc. 71, 863-866(1994).

4) Kilaru, A.; Blancaflor, E. B.; Venables, B. J.; Tripathy, S.; Mysore, K. S.; Chapman, K. D. The $N$-acylethanolamine-mediated regulatory pathway in plants. Chem. Biodivers. 4, 1933-1955 (2007).

5) Venables, B. J.; Waggoner, C. A.; Chapman, K. D. N-acylethanolamines in seeds of selected legumes. Phytochemistry 66, 1913-1918(2005).

6) Schmid, H. H. O.; Schmid, P. C.; Berdyshev, E. V. Cell signaling by endocannabinoids and their congeners: questions of selectivity and other challenges. Chem. Phys. Lipids 121, 111-134(2002).

7) Dalle Carbonare, M.; Del Giudice, E.; Stecca, A.; Colavito, D.; Fabris, M. D.; Arrigo, A.; Bernardini, D.; Dam, M.; Leon, A. A saturated $N$-acylethanolamine other than N-palmitoyl ethanolamine with anti-inflammatory properties: a neglected story $\cdots$. J. Neuroendocrinol. 20, 26-34 (2008).

8) Ezzili, C.; Otrubova, K.; Boger, D. L. Fatty acid amide signaling molecules. Bioorg. Med. Chem. Lett. 20, 5959-5968 (2010).

9) Di Marzo, V.; De Petrocellis, L.; Sepe, N.; Buono, A. Biosynthesis of anandamide and related acylethanolamides in mouse J774 macrophages and N18 neuroblastoma cells. Biochem. J. 316, 977-984(1996).

10) Micale, V.; Cristino, L.; Tamburella, A.; Petrosino, S.; Leggio, G. M.; Drago, F.; Di Marzo, V. Anxiolytic effects in mice of a dual blocker of fatty acid amide hydrolase and transient receptor potential vanilloid type-1 channels. Neuropsychopharmacol. 34, 593-606 (2008).

11) Lin, S.; Khanolkar, A. D.; Fan, P.; Goutopoulos, A.; Qin, C.; Papahadjis, D.; Makriyannis, A. Novel analogues of arachidonylethanolamide (anandamide): affinities for the CB1 and CB2 cannabinoid receptors and metabolic stability. J. Med. Chem. 41, 5353-5361 (1998).

12) di Tomaso, E.; Beltramo, M.; Piomelli, D. Brain cannabinoids in chocolate. Nature 382: 677-678(1996).

13) Wang, X.; Wang, X.; Wang, T.; Synthesis of oleoylethanolamide using lipase. J. Agric. Food Chem. 60, 451457 (2012).

14) Plastina, P.; Meijerink, J.; Vincken, J. P.; Gruppen, H.; Witkamp, R.; Gabriele, B. Selective synthesis of unsat- urated $N$-acylethanolamines by lipase-catalyzed $N$-acylation of ethanolamine with unsaturated fatty acids. Lett. Org. Chem. 6, 444-447 (2009).

15) Maag, H. Fatty acid derivatives: important surfactants for household, cosmetic and industrial purposes. $J$. Am. Oil Chem. Soc. 61, 259-267(1984).

16) Astarita, G.; Di Giacomo, B.; Gaetani, S.; Oveisi, F.; Compton, T. R.; Rivara, S.; Tarzia, G.; Mor, M.; Piomelli, D. Pharmacological characterization of hydrolysis-resistant analogs of oleoylethanolamide with potent anorexiant properties. J. Pharmacol. Exp. Ther. 318, 563-570 (2006).

17) Kolancilar, H. Preparation of laurel oil alkanolamide from laurel oil. J. Am. Oil Chem. Soc. 81, 597-598 (2004).

18) Wang, X.; Wang, T.; Wang, X. An improved method for synthesis of $N$-stearoyl and $N$-palmitoylethanolamine. J. Am. Oil Chem. Soc. 89, 1305-1313(2012).

19) Khanmohammadi, M.; Kojidi, M. H.; Garmarudi, A. B.; Ashuri, A.; Soleymani, M. Quantitative monitoring of the amidation reaction between coconut oil and diethanolamine by attenuated total reflectance fourier transform infrared spectrometry. J. Surfact. Deterg. 12, 37-41 (2009).

20) Semblante, G. U.; Chua, M. T.; Chakraborty, S. Biocatalytic synthesis of diethanolamide surfactants under mild reaction conditions. Philipp. J. Sci. 138, 49-54 (2009).

21) Tufvesson, P.; Annerling, A.; Hatti-Kaul, R.; Adlercreutz, D. Solvent-free enzymatic synthesis of fatty alkanolamides. Biotechnol. Bioeng. 97, 447-453 (2007).

22) O'Connell, A. W. Analysis of coconut oil-diethanolamine condensates by gas chromatography. Anal. Chem. 49, 835-838(1977).

23) Zou, X.; Huang, J.; Jin, Q.; Liu, Y.; Song, Z.; Wang, X. Lipase-catalyzed preparation of human milk fat substitutes from palm stearin in a solvent-free system. $J$. Agric. Food Chem. 59, 6055-6063(2011).

24) Magnusson, C. D.; Haraldsson, G. G. Chemoenzymatic synthesis of symmetrically structured triacylglycerols possessing short-chain fatty acids. Tetrahedron 66, 2728-2731 (2010).

25) Hutcheon, G. A.; Halling, P. J.; Moore, B. D. Measurement and control of hydration in nonaqueous biocatalysis. Method. Enzymol. 286, 465-472 (1997).

26) Kuehl, Jr. F.; Jacob, T.; Ganley, O.; Ormond, R.; Meisinger, M. The identification of $N$-(2-hydroxyethyl)-palmitamide as a naturally occurring anti-inflammatory agent. J. Am. Oil Chem. Soc. 79, 5577-5578(1957). 